\title{
The effect of July admission on inpatient outcomes following spinal surgery
}

\author{
Clinical article
}

\author{
Jennifer S. McDonald, Ph.D., ${ }^{1}$ Michelle J. Clarke, M.D., ${ }^{2}$ \\ Gregory A. Helm, M.D., Ph.D., ${ }^{3}$ And David F. Kallmes, M.D., ${ }^{1,2}$ \\ ${ }^{1}$ Departments of Radiology and ${ }^{2}$ Neurosurgery, Mayo Clinic, Rochester, Minnesota; and ${ }^{3}$ Department of \\ Neurosurgery, University of Virginia Health System, Charlottesville, Virginia
}

\begin{abstract}
Object. The presence of a "July effect," where the influx of new residents and fellows at teaching hospitals every July may negatively affect patient care and outcomes, is widely debated. The authors used the Nationwide Inpatient Sample (NIS) to identify all cases of spinal surgery and examine outcomes among patients who underwent surgery in July compared with those who underwent surgery in other months.

Methods. Spinal surgery hospitalizations from 2001 to 2008 were identified in the NIS by extracting relevant ICD-9 codes. Rates of in-hospital mortality, discharge to a long-term care facility, and postoperative complications were compared between admission months and between teaching and nonteaching hospitals using the Wilcoxon rank-sum test, Fisher exact test, and multivariate regression analysis.

Results. Compared with patients admitted in other months, patients who were admitted to teaching hospitals in July for spinal surgery showed a similar likelihood of in-hospital mortality (OR 0.94 [95\% CI 0.78-1.11], p = 0.46), reaction to implanted device/instrumentation (OR 0.88 [95\% CI 0.77-1.02], $\mathrm{p}=0.09$ ), and postoperative wound dehiscence (OR 1.12 [95\% CI 0.94-1.33], $\mathrm{p}=0.25$ ). A significantly higher likelihood of discharge to a long-term care facility (OR 1.03 [95\% CI 1.00-1.07], $\mathrm{p}=0.0467$ ) and postoperative infection (OR 1.11 [95\% CI 1.05-1.17], $\mathrm{p}=0.0341$ ) was observed in teaching hospitals in July compared with other months; however, incidence rates were similar regardless of admission month. Higher-risk patients (Charlson score $\geq 2$ ) admitted to teaching hospitals in July had a similar likelihood of all outcomes regardless of admission month.

Conclusions. This study of nationwide hospitalizations demonstrates that the influx of new residents and fellows in July has a negligible effect on periprocedural outcomes following spinal surgery. (http://thejns.org/doi/abs/10.3171/2012.12.SPINE12300)
\end{abstract}

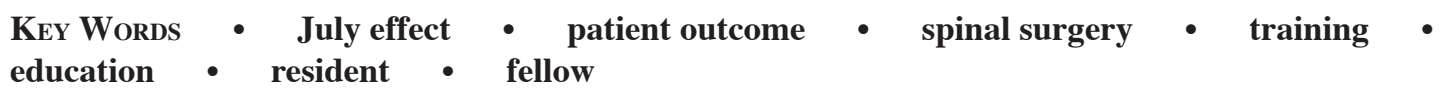

$\mathrm{E}$ VERY July there is an influx of new residents and fellows at teaching hospitals at the start of the academic year. This change in hospital staff has been postulated as a potential source of error that may result in worse patient outcomes in July, also known as the "July effect." However, the results of previous July effect studies have varied, with some studies showing that patients who are admitted in July have outcomes similar to patients presenting in other months $\mathbf{s}^{1,3,4,6,8,11-14,20,24-26}$ and other studies showing worse outcomes in July admissions. ${ }^{9,16,18,23}$ A recent systematic review of 39 July effect studies suggested the presence of a July effect but, over-

\footnotetext{
Abbreviations used in this paper: $\mathrm{IQR}=$ interquartile range; NIS = Nationwide Inpatient Sample.
}

all, was inconclusive. ${ }^{27}$ Additional studies are therefore needed to determine whether patients are at an increased, significant risk of poor outcome in teaching hospitals during these transition months.

Dasenbrock et al. ${ }^{9}$ recently reported that patients with spinal metastatic disease who underwent spinal surgery had higher rates of in-hospital mortality and intraoperative complications in teaching hospitals in July than in other months. However, it is unknown if this pattern is present for all patients undergoing spinal surgery. To examine the potential presence of a July effect in spinal surgery patients, we used the US NIS database from 2001 to 2008 to determine the rate of complications following spinal surgery and to determine whether admission month and hospital teaching status affected these rates. 


\section{Methods}

\section{Data Acquisition}

All spinal surgery hospitalizations were identified from the 2001-2008 NIS hospital discharge database (Healthcare Cost and Utilization Project of the Agency for Healthcare Research and Quality, Rockville, Maryland; www.hcup-us.ahrq.gov/databases.jsp). The NIS is the largest all-payer inpatient database in the US that analyzes national trends in health care utilization outcomes. The data are extracted from a large stratified sample of community hospitals in the US and account for approximately $20 \%$ of annual hospitalizations.

International Classification of Diseases, 9th Revision Clinical Modification diagnostic codes were used to identify all cases of spinal surgery associated with a decompression, discectomy, spinal fusion, or laminectomy as previously described (ICD-9 procedural codes 03.0, 03.09, 03.02, 03.6, 80.50, 80.51, 80.52, 80.59, 81.00, 81.0, $81.04,81.05,81.09,79.50,78.59,78.60,78.69,78.90$, and 78.99). ${ }^{15}$ Data regarding patient demographics (age, sex, and race), hospitalization (admission month, admission type [routine, transfer, or emergency department], and number of diagnoses and chronic diagnoses), hospital demographics (total discharge volume, bedsize [small, medium, or large], ownership [government or private], location [urban or rural], and teaching status [teaching or nonteaching]) were extracted from the NIS data set. The NIS defined teaching hospitals as those that have an American Medical Association-approved residency program, are a member of the Council of Teaching Hospitals, or have a ratio of full-time equivalent interns and residents to beds of 0.25 or higher. Hospitalizations were divided into July admissions and admissions in other months.

Several patient subgroups were created for additional analyses. First, the Charlson comorbidity score was calculated for each patient from relevant ICD-9 diagnostic codes using the Deyo index..$^{10} \mathrm{~A}$ subset of patients with Charlson scores of 2 or higher was created to represent sicker patients with more complications, who might have an increased likelihood of errors in clinical care or might be more affected by such errors. This cutoff was based on a previous report showing that patients with elevated Charlson scores had a higher incidence of mortality following spinal metastasis surgery. ${ }^{2}$ Second, patients were divided into those undergoing simple spinal procedures (discectomy, with or without decompression, or decompression alone) or complex spinal procedures (spinal fusion with or without spinal decompression) to specifically examine those procedures. Third, a subgroup of patients was created that consisted exclusively of elective admissions. The complete spinal surgery population and these various patient subsets were analyzed separately as described below.

In-hospital mortality, discharge disposition, and postoperative complication were the primary outcomes for this study. Postoperative complications were identified using ICD-9 diagnostic codes for surgical site infection (998.5x); infection and inflammatory reaction due to an internal prosthetic device, implant, or graft (996.63, 996.67); or dehiscence of operative wound (998.3x) as previously described. ${ }^{15}$ Data regarding the length of stay and total hospitalization charges were also retrieved. Outcomes were compared both between July admissions and admissions in other months and, separately, between July admissions and June admissions alone.

\section{Statistical Analysis}

Data were extracted from the NIS using SAS software (version 9.2, SAS, Inc.) and were analyzed using JMP (version 9, SAS, Inc.). Continuous data (age, number of diagnoses, Charlson score, total discharge volume, length of stay, and total charges) are presented as medians and interquartile ranges and are compared using the Wilcoxon nonparametric signed-rank test. Categorical data (sex; race; admission type; hospital bedsize, ownership, and location; in-hospital mortality; discharge status; and postoperative complication) are presented as relative frequencies and were compared using the Fisher exact test. Two-tailed tests were used, and statistical significance was defined as $\mathrm{p}<0.05$.

Odds ratios of in-hospital mortality, discharge to long-term care facility, and postoperative complications were calculated using multivariate logistic regression analysis after adjusting for differences in patient and hospitalization characteristics that were significantly different between July admissions and other month admissions for teaching and nonteaching hospitals.

\section{Results}

\section{Patient, Hospitalization, and Hospital Characteristics}

Among 57,663,486 hospitalizations between 2001 and 2008 in the NIS, 968,086 cases of spinal surgery were reported, representing $1.7 \%$ of hospital admissions. Of these procedures, 528,057 (55\%) occurred at teaching hospitals and 440,029 (45\%) occurred at nonteaching facilities. Patient, hospitalization, and hospital characteristics of teaching and nonteaching hospitals are shown in Table 1 . Minor but statistically significant differences between teaching and nonteaching hospitals were observed in all variables because of the large sample size of the study. Patients presenting to teaching hospitals were less likely to be routinely admitted than patients presenting to nonteaching hospitals $(82 \%$ vs $85 \%, \mathrm{p}<0.0001)$. Teaching hospitals had significantly higher total discharge volumes (median 24,495 vs 13,859, p < 0.0001), were more likely to be government controlled (98\% vs $33 \%$, p < 0.0001 ), and were more likely to be in urban locations (97\% vs $91 \%, \mathrm{p}<0.0001)$ than nonteaching hospitals. A higher percentage of teaching hospitals were classified as small bedsize compared with nonteaching hospitals $(15 \%$ vs $11 \%, p<0.0001$ ). However, a direct comparison of this category between teaching and nonteaching hospitals is difficult as the NIS has different bedsize classifications based on hospital teaching status and region (small bedsize for a Midwest teaching hospital is $<249$ beds, small bedsize for a Midwest nonteaching hospital is $<74$ beds).

Patient and hospitalization characteristics of those admitted in July compared with those admitted in other months are shown in Table 2. Again, statistically signifi- 
TABLE 1: Patient, hospitalization, and hospital characteristics by hospital teaching status*

\begin{tabular}{|c|c|c|}
\hline Variable & $\begin{array}{l}\text { Teaching Hospital Admissions } \\
\qquad(\mathrm{n}=528,057)\end{array}$ & $\begin{array}{l}\text { Nonteaching Hospital Admissions } \\
\qquad(n=440,029)\end{array}$ \\
\hline \multicolumn{3}{|l|}{ Patient } \\
\hline median age in yrs & $52(41-64)$ & $53(43-66)$ \\
\hline female sex & $261,778(50 \%)$ & $219,379(50 \%)$ \\
\hline \multicolumn{3}{|l|}{ race } \\
\hline white & $427,357(81 \%)$ & $374,246(85 \%)$ \\
\hline black & $46,130(9 \%)$ & $23,134(5 \%)$ \\
\hline Hispanic & $31,465(6 \%)$ & $26,450(6 \%)$ \\
\hline Asian & $7,311(1 \%)$ & $4,216(1 \%)$ \\
\hline Native American & $2,030(0.3 \%)$ & $1,804(0.3 \%)$ \\
\hline other & $13,764(2 \%)$ & $10,179(2 \%)$ \\
\hline total & 528,057 & 440,029 \\
\hline \multicolumn{3}{|l|}{ Hospitalization } \\
\hline elective admission & $82 \%$ & $85 \%$ \\
\hline \multicolumn{3}{|l|}{ admission type } \\
\hline routine & $474,904(90 \%)$ & $408,337(93 \%)$ \\
\hline transfer & $12,134(2 \%)$ & $4,346(1 \%)$ \\
\hline ED & $41,019(8 \%)$ & $27,346(6 \%)$ \\
\hline total & 528,057 & 440,029 \\
\hline median no. of diagnoses $†$ & $4(2-7)$ & $4(2-7)$ \\
\hline median no. of chronic diagnoses $†$ & $3(2-5)$ & $3(2-5)$ \\
\hline median Charlson score $†$ & $0(0-1)$ & $0(0-1)$ \\
\hline \multicolumn{3}{|l|}{ Hospital } \\
\hline \multicolumn{3}{|l|}{ bedsize } \\
\hline small & $80,477(15 \%)$ & $48,310(11 \%)$ \\
\hline medium & $118,761(22 \%)$ & $91,346(21 \%)$ \\
\hline large & $328,819(62 \%)$ & $300,373(68 \%)$ \\
\hline total & 528,057 & 440,029 \\
\hline government (vs private) & $98 \%$ & $33 \%$ \\
\hline urban (vs rural) & $97 \%$ & $91 \%$ \\
\hline
\end{tabular}

\footnotetext{
* Values represent the number of hospitalizations (\%) unless otherwise specified. Median values are reported as the median $(\mathrm{IQR})$. All comparisons between teaching and nonteaching hospitals were statistically significant $(p<0.05)$. Abbreviation: $E D=$ emergency department.

$\dagger$ Per patient.
}

cant but minor differences in these variables were observed in teaching and nonteaching hospitals. The overall health of patients, as determined by the number of diagnoses, number of chronic diagnoses, and Charlson score, was similar between teaching and nonteaching hospitals.

\section{Incidence and Monthly Trends in Postoperative Complications}

Monthly trends in patient outcomes are shown in Fig. 1. There was a consistently higher incidence of all outcomes reported by teaching hospitals than by nonteaching hospitals. Outcomes including in-hospital mortality, discharge to long-term care facility, postoperative complication, length of stay, and total hospitalization charges are shown in Table 3. Teaching hospitals had small but significantly higher rates of discharge to long-term care facilities $(12.1 \%$ vs $11.5 \%, \mathrm{p}=0.0002)$ and postoperative infection $(1.3 \%$ vs $1.1 \%, \mathrm{p}=0.0005)$ for patients admitted in July than for those admitted in other months. These incidence rates were similar in magnitude, but the differences between July and other month admissions were statistically significant, likely attributable to the large sample size of the study. In contrast, nonteaching hospitals had similar rates of in-hospital mortality, discharge to long-term care facilities, and postoperative complications between July admissions and admissions in other months. Length of stay and total charges, while statistically significant, were similar between July admissions and admissions in other months in both teaching and nonteaching hospitals. 
July admission effect on spinal surgery outcomes

TABLE 2: Patient and hospitalization characteristics by hospital teaching status and admission month*

\begin{tabular}{|c|c|c|c|c|c|c|}
\hline \multirow[b]{2}{*}{ Variable } & \multicolumn{3}{|c|}{ Teaching Hospital Admissions } & \multicolumn{3}{|c|}{ Nonteaching Hospital Admissions } \\
\hline & July $(n=41,211)$ & $\begin{array}{c}\text { Other Mos } \\
(n=486,846)\end{array}$ & $\mathrm{p}$ Value $\dagger$ & July $(n=31,053)$ & $\begin{array}{c}\text { Other Mos } \\
(n=408,976)\end{array}$ & p Value \\
\hline \multicolumn{7}{|l|}{ Patient } \\
\hline median age in yrs & $52(40-64)$ & $52(41-64)$ & $<0.0001$ & $53(42-66)$ & $53(43-66)$ & 0.07 \\
\hline female sex & $20,895(51 \%)$ & $240,883(49 \%)$ & $<0.0001$ & $15,865(51 \%)$ & $203,514(50 \%)$ & $<0.0001$ \\
\hline \multicolumn{7}{|l|}{ race } \\
\hline white & $33,301(81 \%)$ & $394,056(81 \%)$ & $<0.0001$ & $26,035(84 \%)$ & $348,211(85 \%)$ & $<0.0001$ \\
\hline black & $3,726(9 \%)$ & $42,404(9 \%)$ & 0.31 & $1,612(5 \%)$ & $21,522(5 \%)$ & 0.0367 \\
\hline Hispanic & $2,275(6 \%)$ & $29,190(6 \%)$ & 0.0001 & $2,107(7 \%)$ & $24,343(6 \%)$ & 0.0019 \\
\hline Asian & $676(2 \%)$ & $6,635(1 \%)$ & 0.0007 & $387(1 \%)$ & $3,829(1 \%)$ & 0.0002 \\
\hline Native American & $123(0.3 \%)$ & $1,907(0.4 \%)$ & 0.0095 & $120(0.4 \%)$ & $1,684(0.4 \%)$ & 0.34 \\
\hline other & $1,110(2.7 \%)$ & $12,654(2.6 \%)$ & 0.60 & $792(2.6 \%)$ & $9,387(2.3 \%)$ & 0.21 \\
\hline \multicolumn{7}{|l|}{ Hospitalization } \\
\hline $\begin{array}{l}\text { elective admission } \\
\text { admission type }\end{array}$ & $81 \%$ & $82 \%$ & $<0.0001$ & $85 \%$ & $85 \%$ & 0.0006 \\
\hline routine & $36,661(89 \%)$ & $438,243(90 \%)$ & $<0.0001$ & $28,688(92 \%)$ & $379,649(93 \%)$ & $<0.0001$ \\
\hline transfer & $1,100(3 \%)$ & $11,034(2 \%)$ & $<0.0001$ & $359(1 \%)$ & $3,987(1 \%)$ & 0.0066 \\
\hline ED & $3,450(8 \%)$ & $37,569(8 \%)$ & $<0.0001$ & $2,006(6 \%)$ & $25,340(6 \%)$ & 0.15 \\
\hline median no. of diagnosesł & $4(2-7)$ & $4(2-7)$ & 0.42 & $4(2-7)$ & $4(2-7)$ & 0.12 \\
\hline $\begin{array}{l}\text { median no. of chronic } \\
\text { diagnoses } \ddagger\end{array}$ & $3(2-5)$ & $3(2-5)$ & 0.60 & $3(2-5)$ & $3(2-5)$ & 0.0035 \\
\hline median Charlson scoreł & $0(0-1)$ & $0(0-1)$ & 0.18 & $0(0-1)$ & $0(0-1)$ & 0.0204 \\
\hline
\end{tabular}

* Values represent the number of hospitalizations (\%) unless otherwise specified. Median values are reported as the median (IQR).

$\dagger$ Values in boldface are statistically significant.

$\ddagger$ Per patient.

\section{Effect of Admission Month on Patient Outcome}

Multivariate logistic regression analysis was performed to adjust for patient and hospitalization characteristics that were significantly different between July admissions and other month admissions for teaching and nonteaching hospitals. Unadjusted and adjusted odds ratios of in-hospital mortality, discharge to a long-term care facility, and postoperative complication for teaching and nonteaching hospitals are shown in Table 4. After adjustment, patients admitted to nonteaching hospitals in July for spinal surgery showed a similar likelihood of in-hospital mortality $(\mathrm{p}=0.46)$, discharge to longterm care facility $(\mathrm{p}=0.28)$, postoperative infection $(\mathrm{p}$ $=0.12)$, reaction to implanted device/instrumentation $(\mathrm{p}$ $=0.91)$, and postoperative wound dehiscence $(p=0.25)$ as patients who presented in other months. Patients admitted to teaching hospitals in July also showed a similar likelihood for in-hospital mortality $(\mathrm{p}=0.46)$, reaction to implanted device/instrumentation $(\mathrm{p}=0.09)$, and postoperative wound dehiscence $(p=0.20)$, but a significantly higher likelihood of discharge to long-term care facility (OR 1.03 [95\% CI 1.00-1.07], $\mathrm{p}=0.0467$ ) and postoperative infection (OR 1.11 [95\% CI 1.05-1.17], $\mathrm{p}=$ 0.0341 ) than patients admitted in other months. A separate comparison between patients admitted in June and those admitted in July demonstrated similar likelihoods of all outcomes except for a slightly higher likelihood of postoperative wound dehiscence (OR 1.32 [95\% CI 1.031.70], $\mathrm{p}=0.0301$ ) in teaching hospitals in July admissions compared with June admissions (Appendix Tables 1-3). The likelihood of this complication was similar in nonteaching hospitals when comparing July and June admissions $(\mathrm{p}=0.14)$.

\section{Analysis of Higher-Risk Patients}

Since our study population consisted of both healthier, low-risk patients and sicker, high-risk patients who may be more affected by errors in clinical care, a potential July effect in these sicker patients may have been masked. To account for this, the above analyses were repeated with a higher-risk subset of patients with a Charlson score of 2 or higher. This subset consisted of 173,268 patients with a similar distribution between teaching ( $18.3 \%$ of all cases) and nonteaching (17.4\% of all cases) hospitals. The demographics, outcome incidences, and odds ratios of outcomes are shown in Appendix Tables 4-7. Patients in this higher-risk group were older; had fewer elective, routine, and transfer admissions; and had more diagnoses than the entire spinal surgery population. A higher incidence of in-hospital mortality, discharge to long-term care facility, and postoperative complications, longer length of stay, and higher total hospitalization charges was observed in 

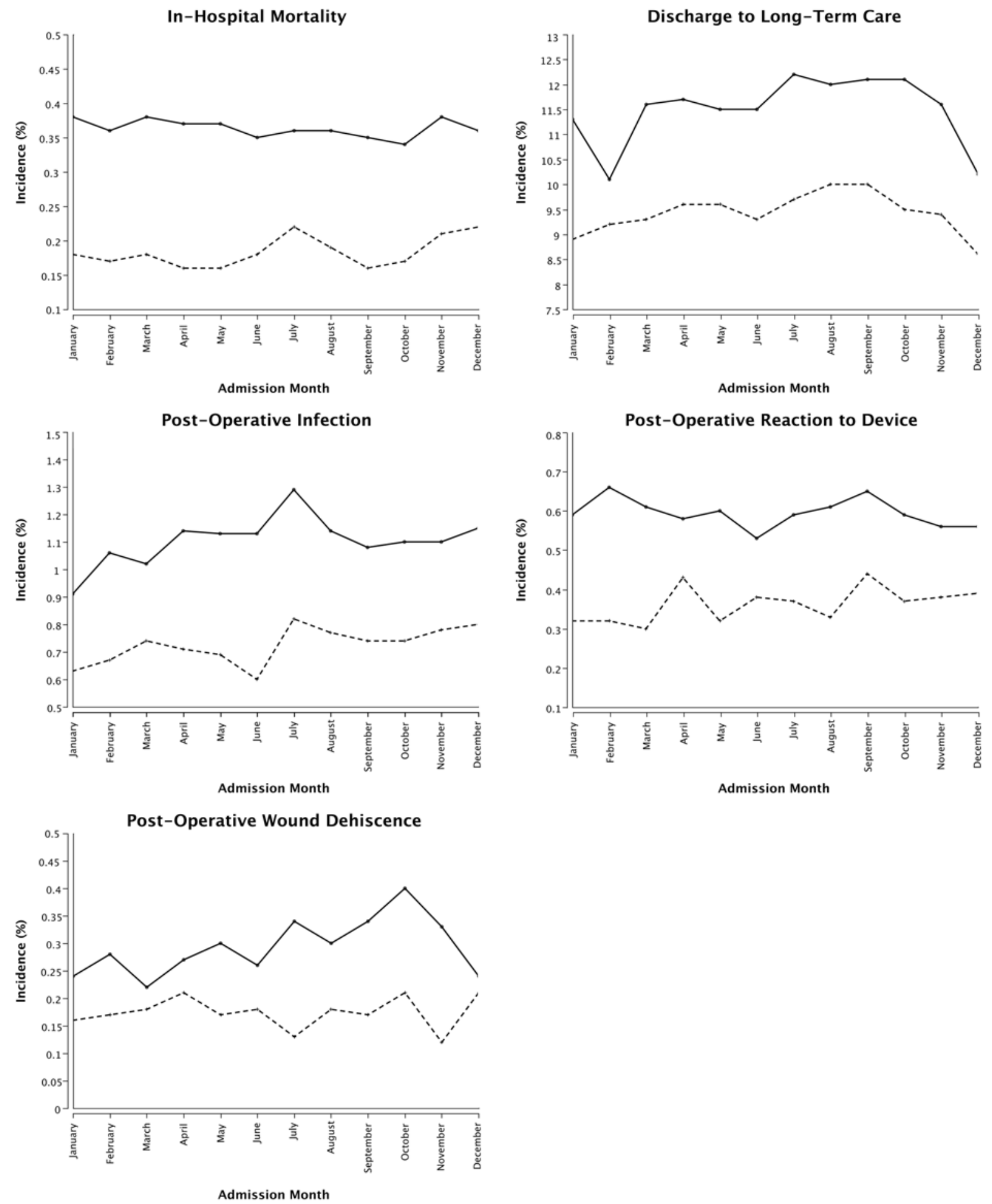

Fig. 1. Incidence of outcomes by admission month and hospital teaching status. The solid line represents teaching hospitals and the dashed line represents nonteaching hospitals.

these patients compared with the entire population. After adjustment, patients admitted to teaching hospitals in July for spinal surgery showed a likelihood of all outcomes similar to patients admitted in other months. However, patients admitted to nonteaching hospitals in July had a significantly higher likelihood of in-hospital mortality
(OR 1.40 [95\% CI 1.02-1.87], $\mathrm{p}=0.0392$ ) and postoperative infection (OR 1.44 [95\% CI 1.16-1.77], $\mathrm{p}=0.0011$ ) than patients admitted in other months.

Analysis of Elective Admissions

Our study population consisted of emergency depart- 
July admission effect on spinal surgery outcomes

TABLE 3: Patient outcomes*

\begin{tabular}{|c|c|c|c|c|c|c|}
\hline \multirow[b]{2}{*}{ Variable } & \multicolumn{3}{|c|}{ Teaching Hospital Admissions } & \multicolumn{3}{|c|}{ Nonteaching Hospital Admissions } \\
\hline & $\begin{array}{c}\text { July } \\
(n=41,211)\end{array}$ & $\begin{array}{c}\text { Other Mos } \\
(n=486,846)\end{array}$ & p Value & $\begin{array}{c}\text { July } \\
(n=31,053)\end{array}$ & $\begin{array}{c}\text { Other Mos } \\
(n=408,976)\end{array}$ & $p$ Value \\
\hline in-hospital mortality & $150(0.4 \%)$ & $1,789(0.4 \%)$ & 0.96 & $68(0.2 \%)$ & $775(0.2 \%)$ & 0.25 \\
\hline $\begin{array}{l}\text { discharge to long-term } \\
\text { care facility }\end{array}$ & $4,996(12.1 \%)$ & $56,043(11.5 \%)$ & 0.0002 & $3,003(9.7 \%)$ & $40,356(9.9 \%)$ & 0.27 \\
\hline postop complication & $808(2.0 \%)$ & $8,748(1.8 \%)$ & 0.0179 & $378(1.2 \%)$ & $4,678(1.1 \%)$ & 0.25 \\
\hline infection & $533(1.3 \%)$ & $5,358(1.1 \%)$ & 0.0005 & $254(0.8 \%)$ & $2,983(0.7 \%)$ & 0.08 \\
\hline reaction to device & $243(0.6 \%)$ & $2,956(0.6 \%)$ & 0.69 & $116(0.4 \%)$ & $1,495(0.4 \%)$ & 0.81 \\
\hline wound dehiscence & $141(0.3 \%)$ & $1,443(0.3 \%)$ & 0.11 & $41(0.1 \%)$ & $736(0.2 \%)$ & 0.06 \\
\hline $\begin{array}{l}\text { median length of stay } \\
\text { in days }\end{array}$ & $2(1-5)$ & $2(1-5)$ & $<0.0001$ & $2(1-4)$ & $2(1-4)$ & 0.0005 \\
\hline $\begin{array}{l}\text { median total charges } \\
\text { in } \$\end{array}$ & $25,061(13,485-53,358)$ & $25,277(13,751-52,422)$ & 0.23 & $24,691(13,473-49,333)$ & $25,676(14,222-50,174)$ & $<0.0001$ \\
\hline
\end{tabular}

* Values represent the number of hospitalizations (\%) unless otherwise specified. Median values are reported as the median (IQR).

ment and transfer admissions, likely representing emergency spinal trauma cases, and elective admissions, likely representing less urgent cases. A subgroup of patients that was electively admitted $(n=712,728)$ was created to examine the July effect in these less urgent cases (Appendix Tables 8-10). Following adjustment, a similar likelihood of all complications was observed between July admissions and other month admissions at both teaching and nonteaching hospitals.

\section{Analysis of Specific Spinal Procedures}

Patients who underwent simple spine procedures (discectomy, with or without decompression, or decompression alone $[\mathrm{n}=509,374])$ or complex spinal procedures (spinal fusion with or without spinal decompression $[\mathrm{n}=420,475]$ ) were identified (Appendix Tables 11-16). A similar likelihood of all complications in July compared with those in other months was observed in

TABLE 4: Odds ratios of outcomes

\begin{tabular}{|c|c|c|c|c|}
\hline \multirow[b]{2}{*}{ Variable } & \multicolumn{2}{|l|}{ Teaching Hospital Admissions } & \multicolumn{2}{|c|}{ Nonteaching Hospital Admissions } \\
\hline & OR of July vs Other Mos $(95 \% \mathrm{Cl})$ & $p$ Value & OR of July vs Other Mos $(95 \% \mathrm{Cl})$ & $\mathrm{p}$ Value \\
\hline \multicolumn{5}{|l|}{ in-hospital mortality } \\
\hline unadjusted & $0.99(0.83-1.17)$ & 0.91 & $1.16(0.89-1.47)$ & 0.26 \\
\hline adjusted* & $0.94(0.78-1.11)$ & 0.46 & $0.72(0.25-1.61)$ & 0.46 \\
\hline \multicolumn{5}{|c|}{ discharge to long-term care facility } \\
\hline unadjusted & $1.06(1.03-1.09)$ & 0.0002 & $0.98(0.94-1.02)$ & 0.27 \\
\hline adjusted & $1.03(1.00-1.07)$ & 0.0467 & $1.06(0.95-1.18)$ & 0.28 \\
\hline \multicolumn{5}{|l|}{ any complication } \\
\hline unadjusted & $1.09(1.02-1.17)$ & 0.0180 & $1.06(0.96-1.18)$ & 0.25 \\
\hline adjusted & $1.03(0.95-1.11)$ & 0.54 & $1.12(0.85-1.44)$ & 0.41 \\
\hline \multicolumn{5}{|l|}{ postop infection } \\
\hline unadjusted & $1.18(1.08-1.29)$ & 0.0005 & $1.12(0.98-1.27)$ & 0.08 \\
\hline adjusted & $1.11(1.05-1.17)$ & 0.0341 & $1.31(0.93-1.79)$ & 0.12 \\
\hline \multicolumn{5}{|l|}{ reaction to device } \\
\hline unadjusted & $0.97(0.85-1.10)$ & 0.66 & $1.02(0.84-1.23)$ & 0.82 \\
\hline adjusted & $0.88(0.77-1.02)$ & 0.09 & $0.98(0.61-1.47)$ & 0.91 \\
\hline \multicolumn{5}{|c|}{ postop wound dehiscence } \\
\hline unadjusted & $1.15(0.97-1.37)$ & 0.11 & $0.73(0.23-0.99)$ & 0.0430 \\
\hline adjusted & $1.12(0.94-1.33)$ & 0.20 & $0.64(0.25-1.33)$ & 0.25 \\
\hline
\end{tabular}

* Multivariate adjustment for variables that were significantly different between July and other month admissions for teaching (age, sex, race, admission source, and elective admission) and nonteaching (age, sex, race, admission source, elective admission, number of chronic diagnoses, and Charlson score) hospitals. 


\section{J. S. McDonald et al.}

both teaching and nonteaching hospitals for simple spine procedures. However, a higher likelihood of discharge to a long-term care facility (OR 1.12 [95\% CI 1.06-1.17], $\mathrm{p}<0.0001$ ) and postoperative infection (OR 1.24 [95\% CI 1.04-1.48], $\mathrm{p}=0.0187$ ) in July compared with other admission months was observed with the complex spine procedures at teaching hospitals. While these odds ratios were statistically significant, the incidence rates of discharge to a care facility (15\% in July vs $13 \%$ in other months) and postoperative infection (1.0\% in July vs $0.7 \%$ in other months) were similar among the July and other month cohorts. A similar likelihood of these outcomes was observed between July admissions and admissions in other months at nonteaching hospitals $(\mathrm{p}=0.69$ and $\mathrm{p}=$ 0.20 , respectively).

\section{Discussion}

The results of this retrospective review of almost 1 million hospitalizations suggest that a minor to negligible July effect may be present in patients undergoing spinal surgery. We observed an increased likelihood of discharge to a long-term care facility and postoperative infection in July admissions compared with admissions in other months and an increased likelihood of postoperative wound dehiscence in July admissions compared with June admissions in teaching hospitals, with no similar increase observed in nonteaching hospitals. As these complications are wound related and are often under the purview of residents and fellows, this higher likelihood in July suggests the presence of a learning curve. However, while this increased incidence was statistically significant, likely because of the large sample size of our study, the magnitude of the difference was quite small. Patients who underwent a complex spinal procedure at teaching hospitals in July also had a higher likelihood of discharge to long-term care facilities and postoperative infection than those who underwent these procedures during other months, with minimal differences in the actual incidence rates of these outcomes. No differences in in-hospital mortality or other postoperative complications were observed between July admissions and admissions in other months. Furthermore, a July effect was not observed in higher-risk patients, patients who were electively admitted, or patients who underwent a simple spinal procedure. These findings suggest that the arrival of new residents and fellows in July likely has a minimal effect on periprocedural outcomes following spinal surgery.

It is surprising that a minimal July effect is observed in the overall patient cohort but is not observed in higherrisk patients. There are several possible explanations for these findings. First, the minor July effect in the overall cohort may be significant only due to the very large sample sizes in this study. The overall incidence rates of complications were similar regardless of admission month. Second, patients with Charlson scores of 2 or higher may not be representative of truly high-risk patients. Third, patients with multiple comorbidities may have received more focused and attentive care because they were higher-risk patients, and residents and fellows may have been less involved in the care of these patients. However, evidence of a July effect was also not observed in the subset of patients who were electively admitted, representing less urgent cases that may have been more likely to be monitored by residents and fellows. Conclusions based on resident or fellow involvement cannot be made, as detailed information on whether residents or fellows were involved in a spinal surgery case and the extent to which they may have been involved is not available in the NIS.

Dasenbrock et al. ${ }^{9}$ reported the presence of a July effect in patients with metastatic spinal disease who underwent spinal surgery; however, the outcomes that were affected by admission month were different. That study reported a higher incidence of in-hospital mortality and intraoperative complications but a similar incidence of nonroutine discharge and postoperative complications in patients who were admitted to teaching hospitals in July compared with those admitted in other months. Several differences between that study and ours may explain these minor discrepancies. First, the Dasenbrock et al. study focused on a smaller subset of patients with diagnosed spinal metastases who underwent a more complex procedure and were likely sicker and more in need of urgent care than our general spinal surgery population. This subset therefore may have been more susceptible to clinical errors and poorer outcomes than our population. Although we found that higher-risk patients in our study were even less likely to be negatively affected by a July admission to a teaching hospital than the entire spinal surgery population, we cannot discount other potential differences in the patient and hospital demographics between studies. Second, the specific types of spinal surgery and outcomes that were examined were different between the studies.

The overall higher incidence of poor outcomes following spinal surgery in teaching hospitals compared with nonteaching hospitals corroborates with other studies that have shown this difference ${ }^{17,22}$ and conflicts with studies that have shown no difference or worse outcomes in nonteaching hospitals. ${ }^{19-21,28}$ These studies analyzed different patient populations and procedures, different time periods, different outcomes, and different hospitals, which may explain their conflicting results. Patients who underwent spinal surgery at teaching hospitals may have been sicker or were in more tenuous health states than patients who underwent procedures at nonteaching hospitals. We did not find substantial differences in the number of diagnoses or Charlson scores in patients admitted to teaching and nonteaching hospitals. Furthermore, higherrisk patients with an elevated Charlson score also showed a higher incidence of poor outcomes in teaching hospitals than patients at nonteaching hospitals. However, patients admitted to teaching hospitals were less likely to be electively admitted and more likely to be transferred. Furthermore, patients admitted to teaching hospitals may have been more likely to have other acute clinical situations not reflected in the NIS that may have contributed to poorer outcomes.

There are several potential reasons why previous July effect studies show such conflicting results. First, studies that focus on a single hospital or region will likely reflect patient demographics and clinical routines specific to that area, while studies of national data will show a much more inclusive picture. Second, a significant het- 
erogeneity of patients and reasons for hospitalization have been studied, including subarachnoid hemorrhage, hip fracture, cardiac surgery, and childbirth. . $^{3,13,20}$ The clinical specialties and subspecialties involved in the care of these patients undoubtedly vary in how they incorporate and supervise residents and fellows. These studies may also have had different distributions of low-risk, healthier patients and higher-risk, sicker, patients with more complications. Finally, some studies did not use a control group of nonteaching hospitals and therefore cannot conclude that any increased incidence of poor outcomes in July hospitalizations is attributable to new residents and fellows instead of seasonal variation or factors that affect both teaching and nonteaching hospitals. ${ }^{16,18}$

Our study has several strengths. Since the NIS is the largest all-payer national inpatient database, it enables a comprehensive analysis of patterns and trends on a nationwide level, avoiding regional and practice biases potentially present in smaller, more local studies. In addition, the NIS contains detailed information regarding patient, hospitalization, and hospital characteristics that can be used to identify and minimize potential confounders that are often present in retrospective studies.

There are several limitations with this study. First, detailed information regarding residency and fellowship programs, including whether a spine program or specific spine fellowship exists, the trainee to bed ratio, amount of supervision, and how residents and fellows are incorporated specifically into postoperative care of spinal surgery patients, is not available in the NIS. Some teaching hospitals may more closely supervise new residents and fellows or limit the number of procedures residents and fellows perform during July compared with other teaching hospitals; however, this level of detail cannot be discerned. Second, the large number of hospitalizations included in this study resulted in differences between patient groups that were statistically significant, yet the magnitude of the differences was actually quite small. Third, coding inaccuracies in administrative databases including the NIS have been reported, which can affect these retrospective evaluations. ${ }^{5}$ However, these inaccuracies are more likely to be systematic errors not specific to month of admission or hospital teaching status. Finally, while we attempted to identify and adjust for all patient and hospital variables that were significantly different between admission month and hospital teaching status, it is possible that other variables not detailed in the NIS may have affected the incidence of outcomes in this study. A prospective study of multiple teaching and nonteaching hospitals over a multiyear period would provide more evidence regarding the presence of a July effect in spinal surgery cases.

\section{Conclusions}

This study of nationwide hospitalizations over an 8-year period indicates that the influx of new residents and fellows in July has a negligible effect on periprocedural outcomes following spinal surgery.

\section{Disclosure}

The authors report no conflict of interest concerning the mate- rials or methods used in this study or the findings specified in this paper.

Author contributions to the study and manuscript preparation include the following. Conception and design: all authors. Acquisition of data: McDonald. Analysis and interpretation of data: McDonald, Clarke, Kallmes. Drafting the article: McDonald, Clarke, Kallmes. Critically revising the article: all authors. Reviewed submitted version of manuscript: all authors. Approved the final version of the manuscript on behalf of all authors: McDonald. Statistical analysis: McDonald.

\section{Appendix}

This article contains an appendix that is available only in the online version of the article.

\section{References}

1. Alshekhlee A, Walbert T, DeGeorgia M, Preston DC, Furlan AJ: The impact of Accreditation Council for Graduate Medical Education duty hours, the July phenomenon, and hospital teaching status on stroke outcomes. J Stroke Cerebrovasc Dis 18:232-238, 2009

2. Arrigo RT, Kalanithi P, Cheng I, Alamin T, Carragee EJ, Mindea SA, et al: Predictors of survival after surgical treatment of spinal metastasis. Neurosurgery 68:674-681, 2011

3. Bakaeen FG, Huh J, LeMaire SA, Coselli JS, Sansgiry S, Atluri PV, et al: The July effect: impact of the beginning of the academic cycle on cardiac surgical outcomes in a cohort of 70,616 patients. Ann Thorac Surg 88:70-75, 2009

4. Barry WA, Rosenthal GE: Is there a July phenomenon? The effect of July admission on intensive care mortality and length of stay in teaching hospitals. J Gen Intern Med 18:639-645, 2003

5. Berthelsen CL: Evaluation of coding data quality of the HCUP National Inpatient Sample. Top Health Inf Manage 21:10-23, 2000

6. Borenstein SH, Choi M, Gerstle JT, Langer JC: Errors and adverse outcomes on a surgical service: what is the role of residents? J Surg Res 122:162-166, 2004

7. Browne JA, Cook C, Olson SA, Bolognesi MP: Resident dutyhour reform associated with increased morbidity following hip fracture. J Bone Joint Surg Am 91:2079-2085, 2009

8. Bruckner TA, Carlo WA, Ambalavanan N, Gould JB: Neonatal mortality among low birth weight infants during the initial months of the academic year. J Perinatol 28:691-695, 2008

9. Dasenbrock HH, Clarke MJ, Thompson RE, Gokaslan ZL, Bydon A: The impact of July hospital admission on outcome after surgery for spinal metastases at academic medical centers in the United States, 2005 to 2008. Cancer 118:14291438,2012

10. Deyo RA, Cherkin DC, Ciol MA: Adapting a clinical comorbidity index for use with ICD-9-CM administrative databases. J Clin Epidemiol 45:613-619, 1992

11. Ehlert BA, Nelson JT, Goettler CE, Parker FM, Bogey WM, Powell CS, et al: Examining the myth of the "July Phenomenon" in surgical patients. Surgery 150:332-338, 2011

12. Englesbe MJ, Fan Z, Baser O, Birkmeyer JD: Mortality in medicare patients undergoing surgery in July in teaching hospitals. Ann Surg 249:871-876, 2009

13. Ford AA, Bateman BT, Simpson LL, Ratan RB: Nationwide data confirms absence of 'July phenomenon' in obstetrics: it's safe to deliver in July. J Perinatol 27:73-76, 2007

14. Garcia S, Canoniero M, Young L: The effect of July admission in the process of care of patients with acute cardiovascular conditions. South Med J 102:602-607, 2009

15. Goode AP, Cook C, Gill JB, Tackett S, Brown C, Richardson W: The risk of risk-adjustment measures for perioperative spine infection after spinal surgery. Spine (Phila Pa 1976) 36:752-758, 2011 


\section{J. S. McDonald et al.}

16. Haller G, Myles PS, Taffé P, Perneger TV, Wu CL: Rate of undesirable events at beginning of academic year: retrospective cohort study. BMJ 339:b3974, 2009

17. Holena DN, Hadler R, Wirtalla C, Carr B, Morris JB, Kelz RR: Teaching status: the impact on emergency and elective surgical care in the US. Ann Surg 253:1017-1023, 2011

18. Inaba K, Recinos G, Teixeira PG, Barmparas G, Talving P, Salim A, et al: Complications and death at the start of the new academic year: is there a July phenomenon? J Trauma 68:19-22, 2010

19. Koval KJ, Rust CL, Spratt KF: The effect of hospital setting and teaching status on outcomes after hip fracture. Am J Orthop 40:19-28, 2011

20. McDonald RJ, Cloft HJ, Kallmes DF: Impact of admission month and hospital teaching status on outcomes in subarachnoid hemorrhage: evidence against the July effect. Clinical article. J Neurosurg 116:157-163, 2012

21. Meguid RA, Brooke BS, Perler BA, Freischlag JA: Impact of hospital teaching status on survival from ruptured abdominal aortic aneurysm repair. J Vasc Surg 50:243-250, 2009

22. Nicholson WK, Witter F, Powe NR: Effect of hospital setting and volume on clinical outcomes in women with gestational and type 2 diabetes mellitus. J Womens Health (Larchmt) 18:1567-1576, 2009

23. Phillips DP, Barker GE: A July spike in fatal medication errors: a possible effect of new medical residents. J Gen Intern Med 25:774-779, 2010
24. Schroeppel TJ, Fischer PE, Magnotti LJ, Croce MA, Fabian TC: The "July phenomenon": is trauma the exception? J Am Coll Surg 209:378-384, 2009

25. Smith ER, Butler WE, Barker FG II: Is there a "July phenomenon" in pediatric neurosurgery at teaching hospitals? J Neurosurg 105 (3 Suppl):169-176, 2006

26. van Walraven C, Jennings A, Wong J, Forster AJ: Influence of house-staff experience on teaching-hospital mortality: the "July phenomenon" revisited. J Hosp Med 6:389-394, 2011

27. Young JQ, Ranji SR, Wachter RM, Lee CM, Niehaus B, Auerbach AD: "July effect": impact of the academic year-end changeover on patient outcomes: a systematic review. Ann Intern Med 155:309-315, 2011

28. Zimmerman JE, Shortell SM, Knaus WA, Rousseau DM, Wagner DP, Gillies RR, et al: Value and cost of teaching hospitals: a prospective, multicenter, inception cohort study. Crit Care Med 21:1432-1442, 1993

Manuscript submitted March 22, 2012.

Accepted December 6, 2012.

Please include this information when citing this paper: published online January 29, 2013; DOI: 10.3171/2012.12.SPINE12300.

Address correspondence to: Jennifer S. McDonald, Ph.D., Department of Radiology, Mayo Clinic, 200 1st Street SW, Rochester, Minnesota 55905. email: mcdonald.jennifer@mayo.edu. 
Appendix

Appendix Table 1: Patient and hospitalization characteristics of June and July admissions*

\begin{tabular}{|c|c|c|c|c|c|c|}
\hline \multirow[b]{2}{*}{ Variable } & \multicolumn{3}{|c|}{ Teaching Hospital Admissions } & \multicolumn{3}{|c|}{ Nonteaching Hospital Admissions } \\
\hline & July $(n=41,211)$ & June $(n=42,391)$ & p Value† & July $(n=31,053)$ & June $(n=32,349)$ & p Value \\
\hline \multicolumn{7}{|l|}{ Patient } \\
\hline median age in yrs & $52(40-64)$ & $51(40-64)$ & 0.55 & $53(42-66)$ & $52(42-65)$ & 0.0005 \\
\hline female sex & $20,895(51 \%)$ & $21,676(51 \%)$ & 0.21 & $15,865(51 \%)$ & $16,635(52 \%)$ & 0.22 \\
\hline \multicolumn{7}{|l|}{ race } \\
\hline white & $33,301(81 \%)$ & $34,320(81 \%)$ & 0.63 & $26,035(84 \%)$ & $27,160(84 \%)$ & 0.46 \\
\hline black & $3,726(9 \%)$ & $3,748(9 \%)$ & 0.32 & $1,612(5 \%)$ & $1,626(5 \%)$ & 0.48 \\
\hline Hispanic & $2,275(6 \%)$ & $2,332(6 \%)$ & 0.81 & $2,107(7 \%)$ & $2,157(7 \%)$ & 0.70 \\
\hline Asian & $676(1.6 \%)$ & $642(1.5 \%)$ & 0.21 & $387(1.2 \%)$ & $342(1.1 \%)$ & 0.07 \\
\hline Native American & $123(0.3 \%)$ & $128(0.3 \%)$ & 0.99 & $120(0.4 \%)$ & $155(0.5 \%)$ & 0.13 \\
\hline other & $1,110(2.7 \%)$ & $1,221(2.9 \%)$ & 0.22 & $792(2.6 \%)$ & $809(2.5 \%)$ & 0.83 \\
\hline \multicolumn{7}{|l|}{ Hospitalization } \\
\hline elective admission & $81 \%$ & $83 \%$ & 0.0002 & $85 \%$ & $85 \%$ & 0.08 \\
\hline \multicolumn{7}{|l|}{ admission type } \\
\hline routine & $36,661(89 \%)$ & $38,206(90 \%)$ & $<0.0001$ & $28,688(92 \%)$ & $29,909(93 \%)$ & 0.0356 \\
\hline transfer & $1,100(3 \%)$ & $1,000(2 \%)$ & 0.0109 & $359(1 \%)$ & $341(1 \%)$ & 0.30 \\
\hline ED & $3,450(8 \%)$ & $3,185(8 \%)$ & $<0.0001$ & $2,006(6 \%)$ & $1,999(6 \%)$ & 0.24 \\
\hline median no. of diagnosesł & $4(2-7)$ & $4(2-7)$ & 0.0017 & $4(2-7)$ & $4(2-7)$ & 0.06 \\
\hline median no. of chronic diagnosesł & $3(2-5)$ & $3(2-5)$ & 0.59 & $3(2-5)$ & $3(2-5)$ & 0.10 \\
\hline median Charlson score $\ddagger$ & $0(0-1)$ & $0(0-1)$ & 0.0082 & $0(0-1)$ & $0(0-1)$ & 0.10 \\
\hline
\end{tabular}

* Values represent the number of hospitalizations (\%) unless otherwise specified. Median values are reported as the median (IQR). Abbreviation: ED = emergency department.

$\dagger$ Values in boldface are statistically significant.

$\ddagger$ Per patient.

Appendix Table 2: Patient outcomes of June and July admissions*

\begin{tabular}{|c|c|c|c|c|c|c|}
\hline \multirow[b]{2}{*}{ Variable } & \multicolumn{3}{|c|}{ Teaching Hospital Admissions } & \multicolumn{3}{|c|}{ Nonteaching Hospital Admissions } \\
\hline & July $(n=41,211)$ & June $(n=42,391)$ & $\mathrm{p}$ Value & July $(n=31,053)$ & June $(n=32,349)$ & $\mathrm{p}$ Value \\
\hline in-hospital mortality & $150(0.4 \%)$ & $150(0.4 \%)$ & 0.82 & $68(0.2 \%)$ & $57(0.2 \%)$ & 0.25 \\
\hline $\begin{array}{l}\text { discharge to long-term care } \\
\text { facility }\end{array}$ & $4,996(12 \%)$ & $4,822(11 \%)$ & 0.0008 & $3,003(10 \%)$ & $3,006(9 \%)$ & 0.13 \\
\hline postop complication & $808(2.0 \%)$ & $730(1.7 \%)$ & 0.0108 & $378(1.2 \%)$ & $334(1.0 \%)$ & 0.0316 \\
\hline infection & $533(1.3 \%)$ & $483(1.1 \%)$ & 0.0433 & $254(0.8 \%)$ & $190(0.6 \%)$ & 0.0006 \\
\hline reaction to device & $243(0.6 \%)$ & $226(0.5 \%)$ & 0.29 & $116(0.4 \%)$ & $121(0.4 \%)$ & 0.99 \\
\hline wound dehiscence & $141(0.3 \%)$ & $110(0.3 \%)$ & 0.0315 & $41(0.1 \%)$ & $57(0.2 \%)$ & 0.16 \\
\hline
\end{tabular}


July admission effect on spinal surgery outcomes

Appendix Table 3: Odds ratios of outcomes of July versus June admissions

\begin{tabular}{|c|c|c|c|c|}
\hline \multirow[b]{2}{*}{ Variable } & \multicolumn{2}{|c|}{ Teaching Hospital Admissions } & \multicolumn{2}{|c|}{ Nonteaching Hospital Admissions } \\
\hline & OR of July vs June (95\% Cl) & p Value & OR of July vs June $(95 \% \mathrm{Cl})$ & p Value \\
\hline \multicolumn{5}{|l|}{ in-hospital mortality } \\
\hline unadjusted & $1.03(0.82-1.29)$ & 0.81 & $1.24(0.87-1.77)$ & 0.23 \\
\hline adjusted* & $0.98(0.77-1.27)$ & 0.93 & $1.22(0.86-1.74)$ & 0.27 \\
\hline \multicolumn{5}{|c|}{ discharge to long-term care facility } \\
\hline unadjusted & $1.07(1.03-1.12)$ & 0.0008 & $1.04(0.99-1.10)$ & 0.13 \\
\hline adjusted & $1.03(0.98-1.08)$ & 0.31 & $1.04(0.98-1.09)$ & 0.21 \\
\hline \multicolumn{5}{|l|}{ any complication } \\
\hline unadjusted & $1.14(1.03-1.27)$ & 0.0103 & $1.18(1.02-1.37)$ & 0.0303 \\
\hline adjusted & $1.12(1.00-1.26)$ & 0.0426 & $1.17(1.00-1.35)$ & 0.0435 \\
\hline \multicolumn{5}{|l|}{ postop infection } \\
\hline unadjusted & $1.14(1.00-1.29)$ & 0.0422 & $1.39(1.15-1.68)$ & 0.0006 \\
\hline adjusted & $1.14(1.00-1.31)$ & 0.06 & $1.38(1.14-1.67)$ & 0.0009 \\
\hline \multicolumn{5}{|l|}{ reaction to device } \\
\hline unadjusted & $1.11(0.92-1.33)$ & 0.27 & $1.00(0.77-1.29)$ & 0.97 \\
\hline adjusted & $1.04(0.85-1.26)$ & 0.71 & $0.98(0.76-1.27)$ & 0.90 \\
\hline \multicolumn{5}{|c|}{ postop wound dehiscence } \\
\hline unadjusted & $1.32(1.03-1.70)$ & 0.0288 & $0.75(0.50-1.11)$ & 0.15 \\
\hline adjusted & $1.32(1.03-1.70)$ & 0.0301 & $0.74(0.49-1.10)$ & 0.14 \\
\hline
\end{tabular}

* Multivariate adjustment for variables that were significantly different between July and June admissions for teaching (elective admission, admission source, number of diagnoses, and Charlson score) and nonteaching (admission source) hospitals. 
J. S. McDonald et al.

Appendix Table 4: Patient, hospitalization, and hospital characteristics of higher-risk patient subset by hospital teaching status*

\begin{tabular}{|c|c|c|}
\hline Variable & $\begin{array}{l}\text { Teaching Hospital Admissions } \\
\qquad(n=96,638)\end{array}$ & $\begin{array}{l}\text { Nonteaching Hospital Admissions } \\
\qquad(\mathrm{n}=76,630)\end{array}$ \\
\hline \multicolumn{3}{|l|}{ Patient } \\
\hline median age in yrs & $61(50-71)$ & $63(52-72)$ \\
\hline female sex & $46,150(48 \%)$ & $37,030(48 \%)$ \\
\hline \multicolumn{3}{|l|}{ race } \\
\hline white & $72,907(75 \%)$ & $62,660(82 \%)$ \\
\hline black & $12,135(13 \%)$ & $5,607(7 \%)$ \\
\hline Hispanic & $6,917(7 \%)$ & $5,494(7 \%)$ \\
\hline Asian & $1,754(2 \%)$ & $945(1 \%)$ \\
\hline Native American & $582(0.6 \%)$ & $378(0.5 \%)$ \\
\hline other & $2,343(2.4 \%)$ & $1,546(2.0 \%)$ \\
\hline \multicolumn{3}{|l|}{ Hospitalization } \\
\hline elective admission & $74 \%$ & $79 \%$ \\
\hline \multicolumn{3}{|l|}{ admission type } \\
\hline routine & $80,276(83 \%)$ & $66,917(87 \%)$ \\
\hline transfer & $4,431(5 \%)$ & $1,346(2 \%)$ \\
\hline ED & $11,931(12 \%)$ & $8,367(11 \%)$ \\
\hline median no. of diagnoses $†$ & $7(5-9)$ & $7(5-9)$ \\
\hline median no. of chronic diagnoses $†$ & $5(4-7)$ & $5(4-7)$ \\
\hline median Charlson score $†$ & $2(2-3)$ & $2(2-3)$ \\
\hline \multicolumn{3}{|l|}{ Hospital } \\
\hline total discharges (no. of patients) & $24,460(17,363-34,406)$ & $14,166(8,979-20,522)$ \\
\hline \multicolumn{3}{|l|}{ bedsize } \\
\hline small & $14,042(15 \%)$ & $7,050(9 \%)$ \\
\hline medium & $21,247(22 \%)$ & $15,140(20 \%)$ \\
\hline large & $61,349(63 \%)$ & $54,440(71 \%)$ \\
\hline government (vs private) & $98 \%$ & $34 \%$ \\
\hline urban (vs rural) & $97 \%$ & $91 \%$ \\
\hline
\end{tabular}

* Values represent the number of hospitalizations (\%) unless otherwise specified. Median values are reported as the median (IQR). All comparisons between teaching and nonteaching hospitals were statistically significant $(p<0.05)$.

$\dagger$ Per patient. 
July admission effect on spinal surgery outcomes

Appendix Table 5: Patient and hospitalization characteristics of higher-risk patient subset by hospital teaching status and admission month*

\begin{tabular}{|c|c|c|c|c|c|c|}
\hline \multirow[b]{2}{*}{ Variable } & \multicolumn{3}{|c|}{ Teaching Hospital Admissions } & \multicolumn{3}{|c|}{ Nonteaching Hospital Admissions } \\
\hline & July $(n=7,662)$ & Other Mos $(n=88,976)$ & $\mathrm{p}$ Value & July $(n=5,514)$ & Other Mos $(n=71,116)$ & p Value \\
\hline \multicolumn{7}{|l|}{ Patient } \\
\hline median age in yrs & $61(50-71)$ & $61(50-71)$ & 0.63 & $62(52-72)$ & $63(52-72)$ & 0.66 \\
\hline female sex & $3,636(47 \%)$ & $42,514(48 \%)$ & 0.59 & $2,691(49 \%)$ & $34,339(48 \%)$ & 0.47 \\
\hline \multicolumn{7}{|l|}{ race } \\
\hline white & $5,852(76 \%)$ & $67,057(75 \%)$ & 0.16 & $4,397(80 \%)$ & $58,260(82 \%)$ & $<0.0001$ \\
\hline black & $944(12 \%)$ & $11,191(13 \%)$ & 0.20 & $443(8 \%)$ & $5,164(7 \%)$ & 0.31 \\
\hline Hispanic & $482(6 \%)$ & $6,433(7 \%)$ & 0.0019 & $448(8 \%)$ & $5,048(7 \%)$ & 0.11 \\
\hline Asian & $153(2 \%)$ & $1,601(2 \%)$ & 0.43 & $75(1 \%)$ & $871(1 \%)$ & 0.66 \\
\hline Native American & $34(0.4 \%)$ & $548(0.6 \%)$ & 0.10 & $28(0.5 \%)$ & $350(0.5 \%)$ & 0.99 \\
\hline other & $197(2.6 \%)$ & $2,146(2.4 \%)$ & 0.72 & $123(2.2 \%)$ & $1,423(2.0 \%)$ & 0.57 \\
\hline \multicolumn{7}{|l|}{ Hospitalization } \\
\hline elective admission & $73 \%$ & $74 \%$ & 0.0173 & $79 \%$ & $79 \%$ & 0.44 \\
\hline \multicolumn{7}{|l|}{ admission type } \\
\hline routine & $6,261(82 \%)$ & $74,016(83 \%)$ & 0.25 & $4,808(87 \%)$ & $62,109(87 \%)$ & 0.0196 \\
\hline transfer & $377(5 \%)$ & $4,054(5 \%)$ & 0.13 & $106(2 \%)$ & $1,240(2 \%)$ & 0.43 \\
\hline ED & $1,024(13 \%)$ & $10,906(13 \%)$ & 0.0039 & $600(11 \%)$ & $7,767(11 \%)$ & 0.67 \\
\hline median no. of diagnoses $†$ & $7(5-9)$ & $7(5-9)$ & 0.66 & $7(5-9)$ & $7(5-9)$ & 0.20 \\
\hline median no. of chronic diagnoses $\dagger$ & $5(4-7)$ & $5(4-7)$ & 0.48 & $5(4-7)$ & $5(4-7)$ & 0.09 \\
\hline median Charlson score $†$ & $2(2-3)$ & $2(2-3)$ & 0.82 & $2(2-3)$ & $2(2-3)$ & 0.53 \\
\hline
\end{tabular}

* Values represent the number of hospitalizations (\%) unless otherwise specified. Median values are reported as the median (IQR).

$\dagger$ Per patient.

Appendix Table 6: Higher-risk patient subset outcomes*

\begin{tabular}{|c|c|c|c|c|c|c|}
\hline \multirow[b]{2}{*}{ Variable } & \multicolumn{3}{|c|}{ Teaching Hospital Admissions } & \multicolumn{3}{|c|}{ Nonteaching Hospital Admissions } \\
\hline & July $(n=7662)$ & Other Mos $(n=88,976)$ & $p$ Value & July $(n=5,514)$ & Other Mos $(n=71,116)$ & $\mathrm{p}$ Value \\
\hline in-hospital mortality & $84(1.1 \%)$ & $982(1.1 \%)$ & 0.99 & $47(0.9 \%)$ & $427(0.6 \%)$ & 0.0256 \\
\hline $\begin{array}{l}\text { discharge to long-term } \\
\text { care facility }\end{array}$ & $1,871(25 \%)$ & $21,274(24 \%)$ & 0.32 & $1,082(20 \%)$ & $15,060(21 \%)$ & 0.0082 \\
\hline postop complication & $253(3.3 \%)$ & $2,731(3.1 \%)$ & 0.26 & $131(2.4 \%)$ & $1,376(1.9 \%)$ & 0.0266 \\
\hline infection & $172(2.2 \%)$ & $1,692(1.9 \%)$ & 0.0361 & $98(1.8 \%)$ & $867(1.2 \%)$ & 0.0007 \\
\hline reaction to device & $76(1 \%)$ & $865(1 \%)$ & 0.86 & $27(0.5 \%)$ & $437(0.6 \%)$ & 0.28 \\
\hline wound dehiscence & $46(0.6 \%)$ & $515(0.6 \%)$ & 0.81 & $18(0.3 \%)$ & $249(0.4 \%)$ & 0.91 \\
\hline $\begin{array}{l}\text { median length of stay } \\
\text { in days }\end{array}$ & $4(2-7)$ & $4(2-7)$ & 0.20 & $3(2-5)$ & $3(2-5)$ & 0.30 \\
\hline median total charges in $\$$ & $31,535(15,871-67,490)$ & $32,598(16,672-69,126)$ & 0.0086 & $29,047(15,644-60,008)$ & $30,626(16,296-60,487)$ & 0.0082 \\
\hline
\end{tabular}

* Values represent the number of hospitalizations (\%) unless otherwise specified. Median values are reported as the median (IQR). 
Appendix Table 7: Odds ratios of higher-risk patient subset outcomes

\begin{tabular}{|c|c|c|c|c|}
\hline \multirow[b]{2}{*}{ Variable } & \multicolumn{2}{|l|}{ Teaching Hospital Admissions } & \multicolumn{2}{|c|}{ Nonteaching Hospital Admissions } \\
\hline & OR of July vs Other Mos $(95 \% \mathrm{Cl})$ & $p$ Value & OR of July vs Other Mos $(95 \% \mathrm{Cl})$ & $\mathrm{p}$ Value \\
\hline \multicolumn{5}{|l|}{ in-hospital mortality } \\
\hline unadjusted & $0.99(0.79-1.23)$ & 0.95 & $1.42(1.04-1.90)$ & 0.0290 \\
\hline adjusted $^{*}$ & $0.97(0.77-1.20)$ & 0.76 & $1.40(1.02-1.87)$ & 0.0392 \\
\hline \multicolumn{5}{|c|}{ discharge to long-term care facility } \\
\hline unadjusted & $1.03(0.97-1.09)$ & 0.32 & $0.91(0.85-0.98)$ & 0.0079 \\
\hline adjusted & $1.01(0.96-1.07)$ & 0.68 & $0.90(0.84-0.96)$ & 0.0027 \\
\hline \multicolumn{5}{|l|}{ any complication } \\
\hline unadjusted & $1.08(0.94-1.23)$ & 0.26 & $1.23(1.02-1.47)$ & 0.0274 \\
\hline adjusted & $1.07(0.93-1.21)$ & 0.34 & $1.22(1.01-1.45)$ & 0.0404 \\
\hline \multicolumn{5}{|l|}{ postop infection } \\
\hline unadjusted & $0.84(0.73-0.99)$ & 0.0406 & $1.47(1.18-1.80)$ & 0.0007 \\
\hline adjusted & $1.17(0.99-1.37)$ & 0.0547 & $1.44(1.16-1.77)$ & 0.0011 \\
\hline \multicolumn{5}{|l|}{ reaction to device } \\
\hline unadjusted & $1.02(0.80-1.28)$ & 0.87 & $0.79(0.53-1.15)$ & 0.23 \\
\hline adjusted & $1.01(0.79-1.27)$ & 0.93 & $0.78(0.52-1.13)$ & 0.20 \\
\hline \multicolumn{5}{|c|}{ postop wound dehiscence } \\
\hline unadjusted & $1.03(0.76-1.39)$ & 0.81 & $0.93(0.56-1.46)$ & 0.77 \\
\hline adjusted & $1.03(0.75-1.38)$ & 0.85 & $0.92(0.55-1.44)$ & 0.72 \\
\hline
\end{tabular}

Appendix Table 8: Patient and hospitalization characteristics of elective admission cases by admission month*

\begin{tabular}{|c|c|c|c|c|c|c|}
\hline \multirow[b]{2}{*}{ Variable } & \multicolumn{3}{|c|}{ Teaching Hospital Admissions } & \multicolumn{3}{|c|}{ Nonteaching Hospital Admissions } \\
\hline & July $(n=29,556)$ & Other Mos $(n=353,057)$ & p Value & July $(n=23,120)$ & Other Mos $(n=306,995)$ & $p$ Value \\
\hline \multicolumn{7}{|l|}{ Patient } \\
\hline median age in yrs & $52(41-65)$ & $52(42-64)$ & $<0.0001$ & $53(43-66)$ & $53(43-66)$ & 0.48 \\
\hline female sex & $15,399(52 \%)$ & $177,991(50 \%)$ & $<0.0001$ & $11,956(52 \%)$ & $154,404(50 \%)$ & $<0.0001$ \\
\hline \multicolumn{7}{|l|}{ race } \\
\hline white & $24,154(82 \%)$ & $290,341(82 \%)$ & 0.0006 & $19,488(84 \%)$ & $263,581(86 \%)$ & $<0.0001$ \\
\hline black & $2,444(8 \%)$ & $28,106(8 \%)$ & 0.31 & $1,167(5 \%)$ & $15,297(5 \%)$ & 0.39 \\
\hline Hispanic & $1,582(4 \%)$ & $19,402(5 \%)$ & 0.23 & $1,515(7 \%)$ & $17,064(6 \%)$ & 0.0001 \\
\hline Asian & $493(1.7 \%)$ & $4,712(1.3 \%)$ & 0.0004 & $276(1.2 \%)$ & $2,825(0.9 \%)$ & 0.0042 \\
\hline Native American & $81(0.3 \%)$ & $1,402(0.4 \%)$ & 0.0052 & $87(0.4 \%)$ & $1,054(0.3 \%)$ & 0.74 \\
\hline other & $802(2.7 \%)$ & $9,094(2.6 \%)$ & 0.39 & $587(2.6 \%)$ & $7,174(2.3 \%)$ & 0.42 \\
\hline \multicolumn{7}{|l|}{ Hospitalization } \\
\hline \multicolumn{7}{|l|}{ admission type } \\
\hline routine & $29,222(99 \%)$ & $349,638(99 \%)$ & 0.0353 & $22,751(98 \%)$ & $302,800(99 \%)$ & $<0.0001$ \\
\hline transfer & $293(0.9 \%)$ & $3,041(0.9 \%)$ & 0.0281 & $163(0.7 \%)$ & $1,913(0.6 \%)$ & 0.20 \\
\hline ED & $41(0.1 \%)$ & $378(0.1 \%)$ & 0.14 & $206(0.9 \%)$ & $2,282(0.7 \%)$ & 0.0306 \\
\hline median no. of diagnoses $†$ & $4(2-7)$ & $4(2-7)$ & 0.33 & $4(2-7)$ & $4(2-7)$ & 0.55 \\
\hline median no. of chronic diagnoses $†$ & $3(2-5)$ & $3(2-5)$ & 0.37 & $3(2-5)$ & $3(2-5)$ & 0.0004 \\
\hline median Charlson score $†$ & $0(0-1)$ & $0(0-1)$ & 0.07 & $0(0-1)$ & $0(0-1)$ & 0.0142 \\
\hline
\end{tabular}

* Values represent the number of hospitalizations (\%) unless otherwise specified. Median values are reported as the median (IQR).

$\dagger$ Per patient. 
July admission effect on spinal surgery outcomes

Appendix Table 9: Patient outcomes of elective admission cases*

\begin{tabular}{lccccccc}
\hline & \multicolumn{2}{c}{ Teaching Hospital Admissions } & & \multicolumn{3}{c}{ Nonteaching Hospital Admissions } \\
\cline { 2 - 3 } \multicolumn{1}{c}{ Variable } & $\begin{array}{c}\text { July } \\
(\mathrm{n}=29,556)\end{array}$ & $\begin{array}{c}\text { Other Mos } \\
(\mathrm{n}=353,057)\end{array}$ & $\mathrm{p}$ Value & & $\begin{array}{c}\text { July } \\
(\mathrm{n}=23,120)\end{array}$ & $\begin{array}{c}\text { Other Mos } \\
(\mathrm{n}=306,995)\end{array}$ & $\mathrm{p}$ Value \\
\hline in-hospital mortality & $46(0.2 \%)$ & $484(0.1 \%)$ & 0.41 & & $25(0.1 \%)$ & $243(0.1 \%)$ & 0.15 \\
discharge to long-term care facility & $2,560(9 \%)$ & $30,505(9 \%)$ & 0.89 & & $1,819(8 \%)$ & $24,342(8 \%)$ & 0.76 \\
postop complication & $301(1 \%)$ & $3,530(1 \%)$ & 0.76 & & $142(0.6 \%)$ & $2,010(0.7 \%)$ & 0.50 \\
infection & $187(0.6 \%)$ & $2,052(0.6 \%)$ & 0.26 & & $88(0.4 \%)$ & $1,200(0.4 \%)$ & 0.87 \\
reaction to device & $96(0.3 \%)$ & $1,203(0.3 \%)$ & 0.65 & & $51(0.2 \%)$ & $655(0.2 \%)$ & 0.82 \\
wound dehiscence & $63(0.2 \%)$ & $680(0.2 \%)$ & 0.44 & & $19(0.1 \%)$ & $359(0.1 \%)$ & 0.16 \\
\hline
\end{tabular}

* Values represent the number of hospitalizations (\%) unless otherwise specified. Median values are reported as the median $(I Q R)$.

Appendix Table 10: Odds ratios of outcomes of elective admission cases

\begin{tabular}{|c|c|c|c|c|}
\hline \multirow[b]{2}{*}{ Variable } & \multicolumn{2}{|l|}{ Teaching Hospital Admissions } & \multicolumn{2}{|l|}{ Nonteaching Hospital Admissions } \\
\hline & OR of July vs Other Mos $(95 \% \mathrm{Cl})$ & p Value & OR of July vs Other Mos $(95 \% \mathrm{Cl})$ & $p$ Value \\
\hline \multicolumn{5}{|l|}{ in-hospital mortality } \\
\hline unadjusted & $1.14(0.83-1.52)$ & 0.42 & $1.37(0.88-2.02)$ & 0.15 \\
\hline adjusted $^{*}$ & $1.13(0.83-1.52)$ & 0.42 & $1.29(0.38-3.26)$ & 0.65 \\
\hline \multicolumn{5}{|c|}{ discharge to long-term care facility } \\
\hline unadjusted & $1.00(0.96-1.05)$ & 0.89 & $0.99(0.94-1.04)$ & 0.75 \\
\hline adjusted & $1.00(0.95-1.04)$ & 0.83 & $1.10(0.96-1.24)$ & 0.17 \\
\hline \multicolumn{5}{|l|}{ any complication } \\
\hline unadjusted & $1.02(0.90-1.15)$ & 0.76 & $0.94(0.79-1.11)$ & 0.46 \\
\hline adjusted & $1.01(0.89-1.13)$ & 0.90 & $1.17(0.78-1.68)$ & 0.42 \\
\hline \multicolumn{5}{|l|}{ postop infection } \\
\hline unadjusted & $0.97(0.78-1.20)$ & 0.81 & $1.09(0.93-1.26)$ & 0.27 \\
\hline adjusted & $1.08(0.93-1.26)$ & 0.29 & $1.57(0.94-2.48)$ & 0.08 \\
\hline \multicolumn{5}{|l|}{ reaction to device } \\
\hline unadjusted & $0.95(0.77-1.17)$ & 0.65 & $1.03(0.77-1.36)$ & 0.82 \\
\hline adjusted & $0.93(0.75-1.14)$ & 0.48 & $1.22(0.65-2.08)$ & 0.51 \\
\hline \multicolumn{5}{|c|}{ postop wound dehiscence } \\
\hline unadjusted & $1.11(0.85-1.42)$ & 0.45 & $0.70(0.43-1.09)$ & 0.11 \\
\hline adjusted & $1.09(0.83-1.40)$ & 0.53 & $0.67(0.16-1.82)$ & 0.47 \\
\hline
\end{tabular}

* Multivariate adjustment for variables that were significantly different between July and other month admissions for teaching (age, sex, race, and admission source) and nonteaching (sex, race, admission source, number of chronic diagnoses, and Charlson score) hospitals. 
J. S. McDonald et al.

Appendix Table 11: Patient and hospitalization characteristics of simple surgery cases*

\begin{tabular}{|c|c|c|c|c|c|c|}
\hline \multirow[b]{2}{*}{ Variable } & \multicolumn{3}{|c|}{ Teaching Hospital Admissions } & \multicolumn{3}{|c|}{ Nonteaching Hospital Admissions } \\
\hline & July $(n=21,661)$ & Other Mos $(n=254,720)$ & $p$ Value & July $(n=16,507)$ & Other Mos $(n=216,486)$ & $p$ Value \\
\hline \multicolumn{7}{|l|}{ Patient } \\
\hline median age in yrs & $54(42-68)$ & $54(42-67)$ & 0.07 & $56(43-69)$ & $56(43-69)$ & 0.97 \\
\hline female sex & $10,342(48 \%)$ & $118,261(46 \%)$ & 0.0002 & $7,956(48 \%)$ & $100,866(47 \%)$ & $<0.0001$ \\
\hline \multicolumn{7}{|l|}{ race } \\
\hline white & $17,716(82 \%)$ & $207,741(82 \%)$ & 0.05 & $13,901(84 \%)$ & $185,665(86 \%)$ & $<0.0001$ \\
\hline black & $1,775(8 \%)$ & $20,598(8 \%)$ & 0.96 & $841(5 \%)$ & $10,480(5 \%)$ & 0.85 \\
\hline Hispanic & $1,179(5 \%)$ & $15,131(6 \%)$ & 0.0045 & $1,085(6 \%)$ & $12,432(6 \%)$ & 0.0420 \\
\hline Asian & $365(1.7 \%)$ & $3,632(1.4 \%)$ & 0.0257 & $203(1.2 \%)$ & $2,066(1.0 \%)$ & 0.0280 \\
\hline Native American & $51(0.2 \%)$ & $882(0.3 \%)$ & 0.0212 & $51(0.3 \%)$ & $927(0.4 \%)$ & 0.0244 \\
\hline other & $575(2.7 \%)$ & $6,736(2.6 \%)$ & 0.89 & $426(2.6 \%)$ & $4,916(2.3 \%)$ & 0.25 \\
\hline \multicolumn{7}{|l|}{ Hospitalization } \\
\hline $\begin{array}{l}\text { elective admission } \\
\text { admission type }\end{array}$ & $82 \%$ & $82 \%$ & 0.25 & $83 \%$ & $84 \%$ & 0.0005 \\
\hline routine & $19,524(90 \%)$ & $230,809(91 \%)$ & 0.75 & $15,149(92 \%)$ & $199,331(92 \%)$ & 0.0303 \\
\hline transfer & $495(2 \%)$ & $5,209(2 \%)$ & 0.0206 & $212(1 \%)$ & $2,381(1 \%)$ & 0.0454 \\
\hline ED & $1,642(8 \%)$ & $18,702(7 \%)$ & 0.17 & $1,146(7 \%)$ & $14,774(7 \%)$ & 0.68 \\
\hline median no. of diagnoses $†$ & $4(2-6)$ & $4(2-6)$ & 0.0304 & $4(2-6)$ & $4(2-6)$ & 0.0379 \\
\hline median no. of chronic diagnoses† & $3(2-5)$ & $3(2-5)$ & 0.65 & $3(2-5)$ & $3(2-5)$ & 0.09 \\
\hline median Charlson score $†$ & $0(0-1)$ & $0(0-1)$ & 0.0031 & $0(0-1)$ & $0(0-1)$ & 0.61 \\
\hline
\end{tabular}

* Values represent the number of hospitalizations (\%) unless otherwise specified. Median values are reported as the median (IQR).

$\dagger$ Per patient.

Appendix Table 12: Patient outcomes of simple surgery cases*

\begin{tabular}{|c|c|c|c|c|c|c|}
\hline \multirow[b]{2}{*}{ Variable } & \multicolumn{3}{|c|}{ Teaching Hospital Admissions } & \multicolumn{3}{|c|}{ Nonteaching Hospital Admissions } \\
\hline & July $(n=21,661)$ & Other Mos $(n=254,720)$ & $p$ Value & July $(n=16,507)$ & Other Mos $(n=216,486)$ & $\mathrm{p}$ Value \\
\hline in-hospital mortality & $59(0.3 \%)$ & $823(0.3 \%)$ & 0.23 & $36(0.2 \%)$ & $360(0.2 \%)$ & 0.12 \\
\hline discharge to long-term care facility & $2,151(10 \%)$ & $24,993(10 \%)$ & 0.59 & $1,435(9 \%)$ & $19,923(9 \%)$ & 0.0301 \\
\hline postop complication & $346(1.6 \%)$ & $3,842(1.5 \%)$ & 0.30 & $187(1.1 \%)$ & $2,419(1.1 \%)$ & 0.85 \\
\hline infection & $267(1.2 \%)$ & $2,882(1.1 \%)$ & 0.18 & $154(0.9 \%)$ & $1,861(0.9 \%)$ & 0.32 \\
\hline reaction to device & $59(0.3 \%)$ & $744(0.3 \%)$ & 0.65 & $26(0.2 \%)$ & $428(0.2 \%)$ & 0.31 \\
\hline wound dehiscence & $67(0.3 \%)$ & $640(0.3 \%)$ & 0.11 & $23(0.1 \%)$ & $394(0.2 \%)$ & 0.25 \\
\hline
\end{tabular}

* Values represent the number of hospitalizations (\%) unless otherwise specified. Median values are reported as the median (IQR). 
July admission effect on spinal surgery outcomes

Appendix Table 13: Odds ratios of outcomes of simple surgery cases

\begin{tabular}{|c|c|c|c|c|}
\hline \multirow[b]{2}{*}{ Variable } & \multicolumn{2}{|l|}{ Teaching Hospital Admissions } & \multicolumn{2}{|c|}{ Nonteaching Hospital Admissions } \\
\hline & OR of July vs Other Mos $(95 \% \mathrm{Cl})$ & $\mathrm{p}$ Value & OR of July vs Other Mos $(95 \% \mathrm{Cl})$ & p Value \\
\hline \multicolumn{5}{|l|}{ in-hospital mortality } \\
\hline unadjusted & $0.84(0.64-1.09)$ & 0.19 & $1.31(0.92-1.82)$ & 0.13 \\
\hline adjusted $^{*}$ & $0.83(0.62-1.08)$ & 0.16 & $1.32(0.87-1.91)$ & 0.18 \\
\hline \multicolumn{5}{|c|}{ discharge to long-term care facility } \\
\hline unadjusted & $1.01(0.97-1.06)$ & 0.59 & $0.94(0.89-0.99)$ & 0.0290 \\
\hline adjusted & $0.99(0.95-1.05)$ & 0.84 & $0.96(0.90-1.02)$ & 0.22 \\
\hline \multicolumn{5}{|l|}{ any complication } \\
\hline unadjusted & $1.06(0.95-1.18)$ & 0.31 & $1.01(0.87-1.17)$ & 0.86 \\
\hline adjusted & $1.06(0.94-1.18)$ & 0.33 & $1.00(0.84-1.17)$ & 0.96 \\
\hline \multicolumn{5}{|l|}{ postop infection } \\
\hline unadjusted & $1.09(0.96-1.23)$ & 0.18 & $1.09(0.92-1.28)$ & 0.33 \\
\hline adjusted & $1.09(0.96-1.24)$ & 0.20 & $1.08(0.90-1.29)$ & 0.39 \\
\hline \multicolumn{5}{|l|}{ reaction to device } \\
\hline unadjusted & $0.93(0.71-1.20)$ & 0.60 & $0.80(0.52-1.16)$ & 0.24 \\
\hline adjusted & $0.92(0.70-1.19)$ & 0.55 & $0.76(0.48-1.14)$ & 0.20 \\
\hline \multicolumn{5}{|c|}{ postop wound dehiscence } \\
\hline unadjusted & $1.23(0.95-1.57)$ & 0.11 & $0.77(0.49-1.14)$ & 0.19 \\
\hline adjusted & $1.24(0.95-1.58)$ & 0.11 & $0.79(0.50-1.18)$ & 0.26 \\
\hline
\end{tabular}

* Multivariate adjustment for variables that were significantly different between July and other month admissions for teaching (sex, race, admission type, number of diagnoses, Charlson score) and nonteaching (sex, race, elective admission, admission type, number of diagnoses) hospitals.

Appendix Table 14: Patient and hospitalization characteristics of complex surgery cases*

\begin{tabular}{|c|c|c|c|c|c|c|}
\hline \multirow[b]{2}{*}{ Variable } & \multicolumn{3}{|c|}{ Teaching Hospital Admissions } & \multicolumn{3}{|c|}{ Nonteaching Hospital Admissions } \\
\hline & July $(n=17,709)$ & Other Mos $(n=210,816)$ & $p$ Value & July $(n=13,473)$ & Other Mos $(n=178,477)$ & $p$ Value \\
\hline \multicolumn{7}{|l|}{ Patient } \\
\hline median age in yrs & $49(38-60)$ & $50(41-61)$ & $<0.0001$ & $51(42-62)$ & $52(42-62)$ & 0.0007 \\
\hline female sex & $9,591(54 \%)$ & $111,785(53 \%)$ & 0.0037 & $7,342(54 \%)$ & $95,195(53 \%)$ & 0.0096 \\
\hline \multicolumn{7}{|l|}{ race } \\
\hline white & $14,188(80 \%)$ & $170,071(81 \%)$ & 0.0004 & $11,242(83 \%)$ & $151,266(85 \%)$ & $<0.0001$ \\
\hline black & $1,749(10 \%)$ & $19,589(9 \%)$ & 0.13 & $740(5 \%)$ & $10,160(6 \%)$ & 0.08 \\
\hline Hispanic & $939(5 \%)$ & $12,113(6 \%)$ & 0.0137 & $920(7 \%)$ & $10,634(6 \%)$ & 0.0174 \\
\hline Asian & $289(1.6 \%)$ & $2,765(1.3 \%)$ & 0.0075 & $174(1.3 \%)$ & $1,669(0.9 \%)$ & 0.0032 \\
\hline Native American & $60(0.3 \%)$ & $899(0.4 \%)$ & 0.15 & $62(0.5 \%)$ & $693(0.4 \%)$ & 0.41 \\
\hline other & $484(2.7 \%)$ & $5,379(2.6 \%)$ & 0.38 & $335(2.5 \%)$ & $4,055(2.3 \%)$ & 0.49 \\
\hline \multicolumn{7}{|l|}{ Hospitalization } \\
\hline $\begin{array}{l}\text { elective admission } \\
\text { admission type }\end{array}$ & $13,028(82 \%)$ & $157,949(84 \%)$ & $<0.0001$ & $10,523(87 \%)$ & $140,244(87 \%)$ & 0.41 \\
\hline routine & $15,690(89 \%)$ & $190,449(90 \%)$ & 0.0001 & $12,656(94 \%)$ & $168,563(94 \%)$ & $<0.0001$ \\
\hline transfer & $510(3 \%)$ & $4,852(2 \%)$ & $<0.0001$ & $126(1 \%)$ & $1,327(1 \%)$ & 0.0374 \\
\hline ED & $1,509(9 \%)$ & $15,515(7 \%)$ & $<0.0001$ & $691(5 \%)$ & $8,587(5 \%)$ & 0.23 \\
\hline median no. of diagnoses† & $4(2-7)$ & $4(3-7)$ & 0.29 & $4(2-7)$ & $4(2-7)$ & 0.94 \\
\hline median no. of chronic diagnoses $†$ & $3(2-5)$ & $3(2-5)$ & 0.33 & $3(2-5)$ & $3(2-5)$ & 0.06 \\
\hline median Charlson score† & $0(0-1)$ & $0(0-1)$ & 0.79 & $0(0-1)$ & $0(0-1)$ & 0.0111 \\
\hline
\end{tabular}

* Values represent the number of hospitalizations (\%) unless otherwise specified. Median values are reported as the median (IQR).

$\dagger$ Per patient. 
Appendix Table 15: Patient outcomes of complex surgery cases*

\begin{tabular}{|c|c|c|c|c|c|c|}
\hline \multirow[b]{2}{*}{ Variable } & \multicolumn{3}{|c|}{ Teaching Hospital Admissions } & \multicolumn{3}{|c|}{ Nonteaching Hospital Admissions } \\
\hline & July $(n=17,709)$ & Other Mos $(n=210,816)$ & $\mathrm{p}$ Value & July $(n=13,473)$ & Other Mos $(n=178,477)$ & $\mathrm{p}$ Value \\
\hline in-hospital mortality & $81(0.5 \%)$ & $860(0.4 \%)$ & 0.33 & $31(0.2 \%)$ & $369(0.2 \%)$ & 0.56 \\
\hline discharge to long-term care facility & $2,589(15 \%)$ & $28,073(13 \%)$ & $<0.0001$ & $1,411(11 \%)$ & $18,692(10 \%)$ & 0.99 \\
\hline postop complication & $199(1.1 \%)$ & $1,943(0.9 \%)$ & 0.0093 & $60(0.5 \%)$ & $735(0.4 \%)$ & 0.53 \\
\hline infection & $161(1.0 \%)$ & $1,413(0.7 \%)$ & 0.0004 & $47(0.4 \%)$ & $514(0.3 \%)$ & 0.21 \\
\hline reaction to device & $25(0.1 \%)$ & $330(0.2 \%)$ & 0.69 & $12(0.1 \%)$ & $140(0.1 \%)$ & 0.63 \\
\hline wound dehiscence & $44(0.3 \%)$ & $448(0.2 \%)$ & 0.31 & $8(0.1 \%)$ & $152(0.1 \%)$ & 0.44 \\
\hline
\end{tabular}

* Values represent the number of hospitalizations (\%) unless otherwise specified. Median values are reported as the median (IQR).

Appendix Table 16: Odds ratios of outcomes of complex surgery cases

\begin{tabular}{|c|c|c|c|c|}
\hline \multirow[b]{2}{*}{ Variable } & \multicolumn{2}{|l|}{ Teaching Hospital Admissions } & \multicolumn{2}{|c|}{ Nonteaching Hospital Admissions } \\
\hline & OR of July vs Other Mos $(95 \% \mathrm{Cl})$ & p Value & OR of July vs Other Mos $(95 \% \mathrm{Cl})$ & $\mathrm{p}$ Value \\
\hline \multicolumn{5}{|l|}{ in-hospital mortality } \\
\hline unadjusted & $1.12(0.89-1.40)$ & 0.33 & $1.11(0.76-1.58)$ & 0.57 \\
\hline adjusted* & $1.10(0.85-1.39)$ & 0.46 & $1.11(0.75-1.59)$ & 0.59 \\
\hline \multicolumn{5}{|c|}{ discharge to long-term care facility } \\
\hline unadjusted & $1.12(1.07-1.16)$ & $<0.0001$ & $1.00(0.94-1.06)$ & 0.99 \\
\hline adjusted & $1.12(1.06-1.17)$ & $<0.0001$ & $1.01(0.95-1.08)$ & 0.69 \\
\hline \multicolumn{5}{|l|}{ any complication } \\
\hline unadjusted & $1.22(1.06-1.41)$ & 0.0092 & $1.08(0.82-1.40)$ & 0.56 \\
\hline adjusted & $1.09(0.93-1.28)$ & 0.28 & $1.08(0.82-1.39)$ & 0.59 \\
\hline \multicolumn{5}{|l|}{ postop infection } \\
\hline unadjusted & $1.36(1.15-1.60)$ & 0.0004 & $1.21(0.89-1.62)$ & 0.22 \\
\hline adjusted & $1.24(1.04-1.48)$ & 0.0187 & $1.22(0.89-1.63)$ & 0.20 \\
\hline \multicolumn{5}{|l|}{ reaction to device } \\
\hline unadjusted & $0.90(0.59-1.33)$ & 0.61 & $1.14(0.60-1.96)$ & 0.68 \\
\hline adjusted & $0.64(0.37-1.00)$ & 0.0518 & $1.09(0.57-1.89)$ & 0.77 \\
\hline \multicolumn{5}{|c|}{ postop wound dehiscence } \\
\hline unadjusted & $1.17(0.85-1.58)$ & 0.33 & $0.70(0.31-1.33)$ & 0.29 \\
\hline adjusted & $1.11(0.81-1.50)$ & 0.50 & $0.69(0.31-1.31)$ & 0.48 \\
\hline
\end{tabular}

* Multivariate adjustment for variables that were significantly different between July and other month admissions for teaching (age, sex, race, admission type, elective admission) and nonteaching (age, sex, race, admission type, Charlson score) hospitals. 